\title{
CD40 Agonists Alter the Pancreatic Cancer Microenvironment by Shifting the Macrophage Phenotype toward M1 and Suppress Human Pancreatic Cancer in Organotypic Slice Cultures
}

\author{
Chae Yoon Lim¹, Jae Hyuck Chang², Won Sun Lee', Jeana Kim³, and II Young Park \\ ${ }^{1}$ Institute of Clinical Medicine Research, Departments of ${ }^{2}$ Internal Medicine, ${ }^{3}$ Hospital Pathology, and ${ }^{4}$ Surgery, College of Medicine, \\ The Catholic University of Korea, Seoul, Korea
}

\section{Article Info}

Received July 6, 2021

Revised August 24, 2021

Accepted September 3, 2021

Published online December 21, 2021

\section{Corresponding Author}

Jae Hyuck Chang

ORCID https://orcid.org/0000-0003-1180-2693

E-mail wwjjaang@catholic.ac.kr
Background/Aims: CD40 agonists are thought to generate antitumor effects on pancreatic cancer via macrophages and T cells. We aimed to investigate the role of CD40 agonists in the differentiation of macrophages and treatment of human pancreatic adenocarcinoma.

Methods: Immunohistochemistry was performed on paraffin-embedded surgical blocks from patients with pancreatic cancers to evaluate macrophage phenotypes and their relationship with survival. The effects of CD40 agonists on macrophage phenotypes and human pancreatic cancer were evaluated utilizing cell cocultures and organotypic slice cultures.

Results: $\mathrm{CD}_{163}{ }^{+}$(predominant in M2 macrophages) and FOXP3+ (predominant in regulatory $\mathrm{T}$ cells) expression levels in the tumors were significantly lower in patients with stage IB pancreatic cancer than in those with stage II or III disease $(p=0.002$ and $p=0.003$, respectively). Patients with high $\mathrm{CD}_{163}{ }^{+}$expression had shorter overall survival than those with low $\mathrm{CD} 163^{+}$expression $(p=0.002)$. In vitro treatment of THP-1 macrophages with a CD40 agonist led to an increase in $\mathrm{HLA}_{-} \mathrm{DR}^{+}$(predominant in M1 macrophages) and a decrease in CD163 ${ }^{+}$expression in THP-1 cells. Cell cocultures showed that CD40 agonists facilitate the suppression of PANC-1 human pancreatic cancer cells by THP-1 macrophages. Organotypic slice cultures showed that CD40 agonists alter the pancreatic cancer microenvironment by shifting the macrophage phenotype toward M1 (increase HLA-DR ${ }^{+}$and decrease CD163 ${ }^{+}$expression), decreasing the abundance of regulatory $\mathrm{T}$ cells, and increasing tumor cell apoptosis.

Conclusions: CD163 is related to advanced human pancreatic cancer stages and shorter overall survival. CD40 agonists alter macrophage phenotype polarization to favor the M1 phenotype and suppress human pancreatic cancer. (Gut Liver 2022;16:645-659)

Key Words: CD40 immunoglobulin; CD163 antigen; Macrophages; Pancreatic neoplasm; Tumor microenvironment

\section{INTRODUCTION}

Pancreatic cancer, with the fourth to fifth highest mortality rate among all cancers, presents with profound tumor stroma and a large number of macrophages. ${ }^{1}$ Macrophages are a fundamental part of the innate immune system. However, macrophages within the tumor microenvironment have been associated with the promotion of cancer cell growth, migration, angiogenesis, and immunosuppression. ${ }^{2}$ Macrophages within the tumor, called tumor-associated macrophages (TAMs) have functional plasticity, which may result in the polarized expression of either anti- or protumoral functions known as the M1 or M2 phenotype, respectively. Several studies have highlighted the relationships between TAMs and the prognosis of cancer patients. CD163 (an M2 macrophage marker) predicts the clinical prognosis of patients with intrahepatic cholangiocarcinoma, ${ }^{3}$ and overexpression of CD68 (a panmacrophage marker) and CD163 was associated with a worse outcome in patients with hepatocellular carcinoma. ${ }^{4}$ 
Although there has been some research on TAMs in pancreatic cancer, ${ }^{1,5-7}$ the role of M1 and M2 macrophages in the clinical aspects of pancreatic cancer patients still needs to be clarified. Since TAMs have functional plasticity and exhibit a mixed phenotype with properties of M1 and M2 macrophages, ${ }^{4}$ identifying macrophage phenotypes and controlling phenotype polarization are important for understanding cancer pathogenesis and treating this disease.

CD40 is a cell surface molecule on immune cells and a member of the tumor necrosis factor (TNF) receptor superfamily. ${ }^{8}$ As binding of CD40 to the CD40 ligand triggers activating signals to $\mathrm{CD} 40^{+}$immune cells, ${ }^{8} \mathrm{CD} 40$ antibody agonists were found to mimic the signal of the CD40 ligand. ${ }^{9} \mathrm{CD} 40$ agonists can mediate $\mathrm{T}$ cell-independent and $\mathrm{T}$ cell-dependent immune mechanisms regarding cancer regression, ${ }^{10,11}$ and macrophages are the main effectors in $\mathrm{T}$ cell-independent mechanisms. A previous study suggested that CD40 agonists are involved in the systemic activation of macrophages that infiltrate the tumor and become tumoricidal. ${ }^{10}$ In a murine in vitro model, CD40 agonists generated cancer immunoediting by eliciting M1 macrophages in sarcoma, ${ }^{12}$ and $\mathrm{CD} 40$-activated macrophages inhibited melanoma growth. ${ }^{13,14}$

Herein, we report M2 polarization in human pancreatic cancer and its association with cancer stages and overall survival in patients with pancreatic cancer. Coculture of macrophages and human pancreatic cancer cells showed that CD40 agonist-activated M1 macrophages suppress the proliferation of human pancreatic cancer cells, and organo- typic slice culture demonstrated that CD40 agonists induce M1 differentiation in the tumor microenvironment and increase the apoptosis of human pancreatic cancer cells.

\section{MATERIALS AND METHODS}

\section{Patients and cell lines}

Paraffin-embedded pancreatic cancer blocks from 12 patients (\#1-12) who underwent surgery between 2015 and 2018 were obtained from the tissue bank at our institute. For the treatment of pancreatic cancer, radical antegrade modular pancreatosplenectomy was performed in six patients, a Whipple procedure was performed in four patients, and pylorus-preserving pancreaticoduodenectomy was performed in two patients. The 8th edition American Joint Committee on Cancer stages of pancreatic cancer after surgery were IB for three patients, IIA for four, IIB for three, and III for two. In another eight patients (\#13-20) with pancreatic cancer, pancreatic tumor specimens were procured during surgery for the production of organotypic slice cultures. Overall the characteristics of all 20 patients are listed in Table 1.

For the coculture experiment, a pancreatic adenocarcinoma cell line (PANC-1) and monocyte cell line (THP-1) were purchased from a Korean cell line bank. The passage numbers of the cell lines at the time of purchase were 70 for PANC-1 cells and 13 for THP-1 cells. The cell lines were stored at $-196^{\circ} \mathrm{C}$ prior to use.

Table 1. Patient Characteristics

\begin{tabular}{|c|c|c|c|c|c|c|c|c|c|}
\hline $\begin{array}{l}\text { Patient } \\
\text { No. }\end{array}$ & Age, yr & Sex & Location & $\begin{array}{c}\text { Tumor } \\
\text { differentiation }\end{array}$ & $\begin{array}{c}\text { Tumor size, } \\
\mathrm{cm}\end{array}$ & $\begin{array}{c}\mathrm{T} \\
\text { stage }\end{array}$ & $\begin{array}{c}\mathrm{LN} \\
\text { metastasis }\end{array}$ & $\begin{array}{c}\text { AJCC stage, } \\
\text { 8th }\end{array}$ & $\begin{array}{l}\text { Surgical } \\
\text { procedure }\end{array}$ \\
\hline 1 & 53 & M & Body & Moderate & $3.2 \times 2.8$ & $\mathrm{~T} 2$ & 3/38, N1 & $2 \mathrm{~B}$ & RAMPS \\
\hline 2 & 55 & M & Tail & Well & $3.2 \times 2.3$ & $\mathrm{~T} 2$ & 3/37, N1 & $2 B$ & RAMPS \\
\hline 3 & 65 & $M$ & Tail & Moderate & $4.5 \times 3.5 \times 4.0$ & T3 & 0/7, NO & $2 \mathrm{~A}$ & RAMPS \\
\hline 4 & 55 & $M$ & Head & Moderate & $3.0 \times 2.8$ & $\mathrm{~T} 2$ & O/20, NO & 1B & PPPD \\
\hline 5 & 53 & $M$ & Body & Poor & $2.4 \times 2.0$ & $\mathrm{~T} 2$ & 2/16, N1 & $2 B$ & RAMPS \\
\hline 6 & 65 & F & Head & Moderate & $2.3 \times 1.7$ & $\mathrm{~T} 2$ & 0/2, NO & 1B & RAMPS \\
\hline 7 & 64 & M & Tail & Moderate & $9.5 \times 4.5$ & T3 & $0 / 11$, NO & $2 \mathrm{~A}$ & RAMPS \\
\hline 8 & 68 & $\mathrm{~F}$ & Tail & Moderate & $4.2 \times 3.0 \times 4.5$ & T3 & $0 / 6, \mathrm{NO}$ & $2 \mathrm{~A}$ & Whipple \\
\hline 9 & 55 & $M$ & Head & Poor & $5.0 \times 4.0$ & T3 & $0 / 2, \mathrm{NO}$ & $2 \mathrm{~A}$ & PPPD \\
\hline 10 & 51 & $M$ & Head & Moderate & $3.0 \times 2.5 \times 2.0$ & $\mathrm{~T} 2$ & $6 / 35, N 2$ & 3 & Whipple \\
\hline 11 & 77 & $M$ & Head & Well & $5.0 \times 4.2$ & T3 & $10 / 32, N 2$ & 3 & Whipple \\
\hline 12 & 58 & $\mathrm{~F}$ & Head & Poor & $2.4 \times 2.2$ & $\mathrm{~T} 2$ & $1 / 32$, N1 & $2 B$ & Whipple \\
\hline 13 & 66 & $\mathrm{~F}$ & Head & Adenosquamous & $2.5 \times 2.3$ & $\mathrm{~T} 2$ & 0/27, NO & 1B & Whipple \\
\hline 14 & 59 & M & Head & Moderate & $2.5 \times 2.0 \times 1.0$ & $\mathrm{~T} 2$ & 0/6, NO & $1 \mathrm{~B}$ & Whipple \\
\hline 15 & 58 & $\mathrm{~F}$ & Tail & Poor & $7.0 \times 6.0 \times 5.5$ & T3 & $4 / 14, \mathrm{~N} 2$ & 3 & RAMPS \\
\hline 16 & 53 & $\mathrm{~F}$ & Body & Moderate & $2.8 \times 1.7$ & $\mathrm{~T} 2$ & $2 / 30, N 1$ & 3 & RAMPS \\
\hline 17 & 67 & $\mathrm{~F}$ & Head & Poor & $4.1 \times 4.0$ & $\mathrm{~T} 2$ & $17 / 29, \mathrm{~N} 2$ & 3 & Whipple \\
\hline 18 & 78 & $M$ & Head & Adenosquamous & $1.7 \times 1.6$ & $\mathrm{~T} 1$ & $11 / 25, \mathrm{~N} 2$ & 3 & Whipple \\
\hline 19 & 53 & $\mathrm{~F}$ & Body & Moderate & $2.8 \times 1.7$ & $\mathrm{~T} 2$ & 2/30, N1 & $2 B$ & RAMPS \\
\hline 20 & 54 & $\mathrm{~F}$ & Tail & Adenosquamous & $7.5 \times 5.5$ & T3 & $5 / 32, N 2$ & 3 & RAMPS \\
\hline
\end{tabular}

LN, lymph node; AJCC, American Joint Committee on Cancer; M, male; F, female; RAMPS, radical antegrade modular pancreatosplenectomy; PPPD, pylorus-preserving pancreaticoduodenectomy. 


\section{Coculture of THP-1 and PANC-1 cells}

Human monocytic THP-1 cells maintained in RPMI $1640 / 10 \%$ fetal bovine serum were seeded in 12 -well transwell inserts $(0.4 \mu \mathrm{m}$ pore size $)$ at a concentration of $1 \times 10^{5}$ cells/mL. Settled THP1 cells were treated with $10 \mathrm{ng} / \mathrm{mL}$ 12-O-tetradecanoylphorbol-13-acetate (PMA; Promega, Madison, WI, USA, \#V1171) for 24 hours in an incubation system $\left(37^{\circ} \mathrm{C}, 5 \% \mathrm{CO}_{2}\right)$. The PMA containing media were aspirated gently from the inserts and replaced with media containing with $15 \mathrm{ng} / \mathrm{mL}$ lipopolysaccharide (Sigma, St. Louis, MO, USA, \#L2630); the cells were incubated for 48 hours to allow differentiation into macrophages. Differentiated macrophages within the inserts were transferred onto preplated human PANC- 1 cells $\left(1 \times 10^{5} / \mathrm{mL}\right)$ and cocultured in medium supplemented with $2 \mu \mathrm{g} / \mathrm{mL}$ CD40 antibody (R\&D System, Minneapolis, MN, USA, \#MAB6321-500) or $2 \mu \mathrm{g} / \mathrm{mL}$ isotype monoclonal antibody control (R\&D System, \#MAB004) for 96 hours.

\section{Cell viability test}

Cell viability was evaluated by the CCK-8 assay using a Cell Counting Kit-8 (Dojindo, Incheon, Korea, \#CK04). The viability of cocultured PANC-1 cells was measured according to the protocol provided by the manufacturer. CCK-8 solution was added at 1/10 volume into each well and incubated at $37^{\circ} \mathrm{C}$ in humidified incubator with $5 \%$ $\mathrm{CO}_{2}$ for 2 hours. The absorbance at $450 \mathrm{~nm}$ was measured and recorded using an enzyme-linked immunosorbent assay (ELISA) plate reader (VersaMax; Molecular Devices, Silicon Valley, CA, USA).

\section{Immunofluorescent staining}

Cocultured THP1 cells were attached to slides with a cytospin, fixed in $4 \%$ paraformaldehyde and then rinsed with phosphate-buffered saline. To inhibit nonspecific signals, the slides were exposed to a blocking solution (2\% normal goat serum) at room temperature for 2 hours. Then, the slides were incubated with antibodies against CD163 (1:300 dilution; Abcam Ltd., Cambridge, UK) and HLA-DR (an M1 macrophage marker) (1:300, Abcam Ltd.) overnight at $4{ }^{\circ} \mathrm{C}$. The slide was rinsed with phosphate-buffered saline three times and then incubated with Alexa Fluor 488-labeled goat anti-rabbit IgG secondary antibody (1:600; Molecular Probes, Eugene, OR, USA) at room temperature for 2 hours. The samples were rinsed with phosphate-buffered saline three times before they were stained with 4, 6-diamidino-2-phenylindole (Vector Laboratories, Burlingame, CA, USA) and examined under a fluorescence microscope (BX50; Olympus, Tokyo, Japan).

\section{Immunohistochemistry}

Immunohistochemistry (IHC) was performed using an automated immunohistochemical stainer (Ventana Medical Systems, Inc., Tucson, AZ, USA) according to the manufacturer's protocol. The sections were deparaffinized, pretreated with cell conditioning solution ( $\mathrm{CC} 1$; Ventana), and subjected to ultraviolet radiation to abrogate endogenous peroxidase activity. The primary antibodies were diluted in Dako antibody diluent (DakoCytomation, Glostrup, Denmark) with background-reducing components and targeted the following proteins: CD68 (1:1,000; mouse, Dako), CD163 (1: 2,000; rabbit, Abcam, Franklin Lakes, NJ, USA), HLA-DR (1:10,000; mouse, Abcam), caspase-3 (1:500; rabbit, Cell Signaling Technology, Inc., Danvers, MA, USA) and FOXP3 (1:50; mouse, Abcam). The sections were incubated with primary antibodies at room temperature for 32 minutes and then hybridized with horseradish peroxidase-conjugated secondary antibody (Ventana) for 8 minutes. The reaction was developed with diaminobenzidine (DAB; Dako) for 5 minutes and the slides were counterstained with hematoxylin II (Ventana) for 4 minutes and a bluing reagent (Ventana) for 4 minutes. These sections were finally observed under a light microscope (BX50; Olympus).

\section{Western blot}

Cell lysates were extracted in RIPA lysis buffer containing protease inhibitor cocktail and protein phosphatase inhibitor cocktail for 20 minutes on ice. Total cell lysates were clarified by centrifugation. Protein concentration was determined using a DC protein assay kit (Bio-Rad, Hercules, CA, USA) following the manufacturer's protocol. Protein samples $(30 \mu \mathrm{g})$ were separated by sodium dodecyl sulfate-polyacrylamide gel electrophoresis through $4 \%$ to $20 \%$ gradient gels and transferred to a polyvinylidene fluoride membrane (Roche, Mannheim, Germany), which was blocked with $5 \%$ skim milk in tris-buffered saline with polysorbate 20 for 1 hour at room temperature. Primary antibodies against CD163 (ab189915; Abcam), HLA-DR (ab20181; Abcam), and $\beta$-actin (Cell Signaling Technology, Inc.) were diluted 1:1,000 in TBST. The membranes were incubated overnight at $4{ }^{\circ} \mathrm{C}$ with the primary antibodies and then washed three times with TBST before they were incubated in 1:5,000 horseradish peroxidase-conjugated goat anti-rabbit IgG antibody or goat anti-mouse IgG antibody (Bio-Rad) for 1 hour at room temperature. The membrane was washed in TBST, and the hybridized protein bands were detected with an ECL detection kit (Bio$\mathrm{Rad}$ ) and processed with Image Lab software (Bio-Rad). 


\section{Enzyme-linked immunosorbent assay}

The supernatants of cell cocultures and organotypic slice cultures were subjected to ELISA analysis to quantify the following cytokines: interleukin-10 (IL-10; Invitrogen, Carlsbad, CA, USA), TNF- $\alpha$ (R\&D System), and tumor growth factor (TGF) $\beta$ (R\&D System). The concentrations of cytokines were assessed using standard ELISA methods with a Quantikine kit according to the manufacturer's guidelines.

\section{Organotypic slice culture and drug treatment}

Freshly resected specimens were transferred from the operating room to the laboratory in a $50-\mathrm{mL}$ conical tube containing ice-cold transport medium (HBSS (1X) supplemented with 1X Pen-Strep solution and $500 \mathrm{nmol} / \mathrm{L}$ diphenyl diselenide). Cores $6 \mathrm{~mm}$ in diameter were punched from fresh tumor tissues using a biopsy punch and sliced on a vibratome to a thickness of $250 \mu \mathrm{m}$. The detailed methods for slicing tumors and culture conditions are described in our previous study. ${ }^{15}$ Pancreatic cancer slices were cultured in 6- or 24-well plates with culture media. Tumor slices were cultured for 4 days, and drug treatment was performed on the $2 \mathrm{nd}$ day. CD40 agonists $(2 \mu \mathrm{g} / \mathrm{mL}$ or $10 \mu \mathrm{g} / \mathrm{mL}$ ) or control isotype monoclonal antibodies (2 $\mu \mathrm{g} / \mathrm{mL}$ ) were added to pancreatic cancer slices for 48 hours in an incubation system $\left(37^{\circ} \mathrm{C}, 5 \% \mathrm{CO}_{2}\right)$. Gemcitabine $(0.1$ $\mu \mathrm{M})$ was also administered under all conditions for 48 hours. Then, pancreatic cancer slices were fixed and embedded vertically to include both interfaces of tumor slices (the upper contacts with the air and the lower contacts with the membrane) in the final slides. Paraffin blocks containing three to five pieces of tumor slices were sectioned using a microtome into $3 \mu \mathrm{m}$ thick sections. Hematoxylin and eosin staining, IHC staining (CD68, CD163, HLADR, FOXP3, and caspase-3), Western blotting (CD163 and HLA-DR), and ELISA (IL-10, TNF- $\alpha$, and TGF- $\beta$ ) were performed using the sections or supernatants. Each slide had three to five pieces of tumor.

\section{Image analysis and cell counting}

For IHC evaluation of surgically resected human pancreatic cancers, we selected the most suitable tissue block which contains sufficient tumor and peritumor stroma together, from each patient. Six to eight high-power fields (HPFs, $\times 200$ magnification) of IHC-stained slides that had the greatest staining intensity in each specimen per patient were selected for evaluation of IHC expression. For IHC evaluation of organotypic slice culture tissues, 6 to $12 \mathrm{HPFs}$ $(\times 200$ magnification) of an IHC-stained slide that had the greatest staining intensity were selected and used for counting. All the stained slides including those processed for hematoxylin and eosin and IHC, were scanned using a slide scanner (Aperio CS2; Leica Microsystems, Wetzlar, Germany). Pictures from the scanned slides were captured with an Aperio ImagScope (version 12.3.2.5030; Leica Microsystems). In the captured images ( $\times 200$ magnification), positive pixels corresponding to CD68, CD163, HLA-DR, and caspase- 3 were counted automatically using an ImageJ (NIH, Bethesda, MD, USA), and FOXP3 ${ }^{+}$cells were manually counted.

\section{Ethics statement}

This study was approved by the Institutional Research Board of the Catholic University of Korea (IRB numbers: HC16TNSI0100 and HC20SISI0043). Informed consent was obtained from all patients who had been enrolled. All study protocols were in complete compliance with the Declaration of Helsinki.

\section{Statistical analysis}

Quantitative data are described as the median and interquartile range. Error bars in the figures indicate standard errors. Quantitative variables in each group were compared using the Mann-Whitney U-test. The four cancer stage groups were compared using the Kruskal-Wallis test. Overall survival was plotted by the Kaplan-Meier method and compared by the log-rank test. A p-value $<0.05$ was considered to be significant. SPSS version 20 (IBM Corp., Armonk, NY, USA) or GraphPad Prism 8.4.2 (GraphPad Software, San Diego, CA, USA) were used to conduct the statistical analysis and create the figures.

\section{RESULTS}

\section{Expressions of M2 macrophage and regulatory $T$ cell markers were related to advanced stages}

IHCs of 12 human pancreatic cancers showed positive expression of macrophage markers (CD68, CD163, and HLA-DR) and regulatory T cell marker (FOXP3) (Fig. 1A). Macrophage markers were stained diffusely with high intensity, which indicated that there were many macrophages in human pancreatic cancer tissues. Since these macrophage markers were diffuse throughout the samples and the macrophages could not be distinguished clearly from surroundings, the positive expression of CD68, CD163, and HLA-DR was quantified by ImageJ with stained pixels. The median (interquartile range) positive pixels/HPF were 15,128 (9,402 to 31,583$)$ for CD68, 6,118 (2,730 to 10,833) for CD163, and 4,623 (3,063 to 6,192) for HLA-DR. CD163 ${ }^{+}$expression levels were significantly higher than HLA-DR expression levels ( $<<0.001$ ), which indicates that M2 macrophages were 
more predominant in human pancreatic cancer than M1 macrophages. In contrast to the macrophage-related expression, there were a small number of FOXP3 ${ }^{+}$cells in the tissues of pancreatic cancer. Because FOXP3 was detected in only small round cells (T lymphocytes), FOXP3 ${ }^{+}$small cells were manually counted. The median number (interquartile range) of $\mathrm{FOXP}^{+}$cells in human pancreatic cancer tissues was 7.5 (2.0 to 14.2$)$ cells/HPF.
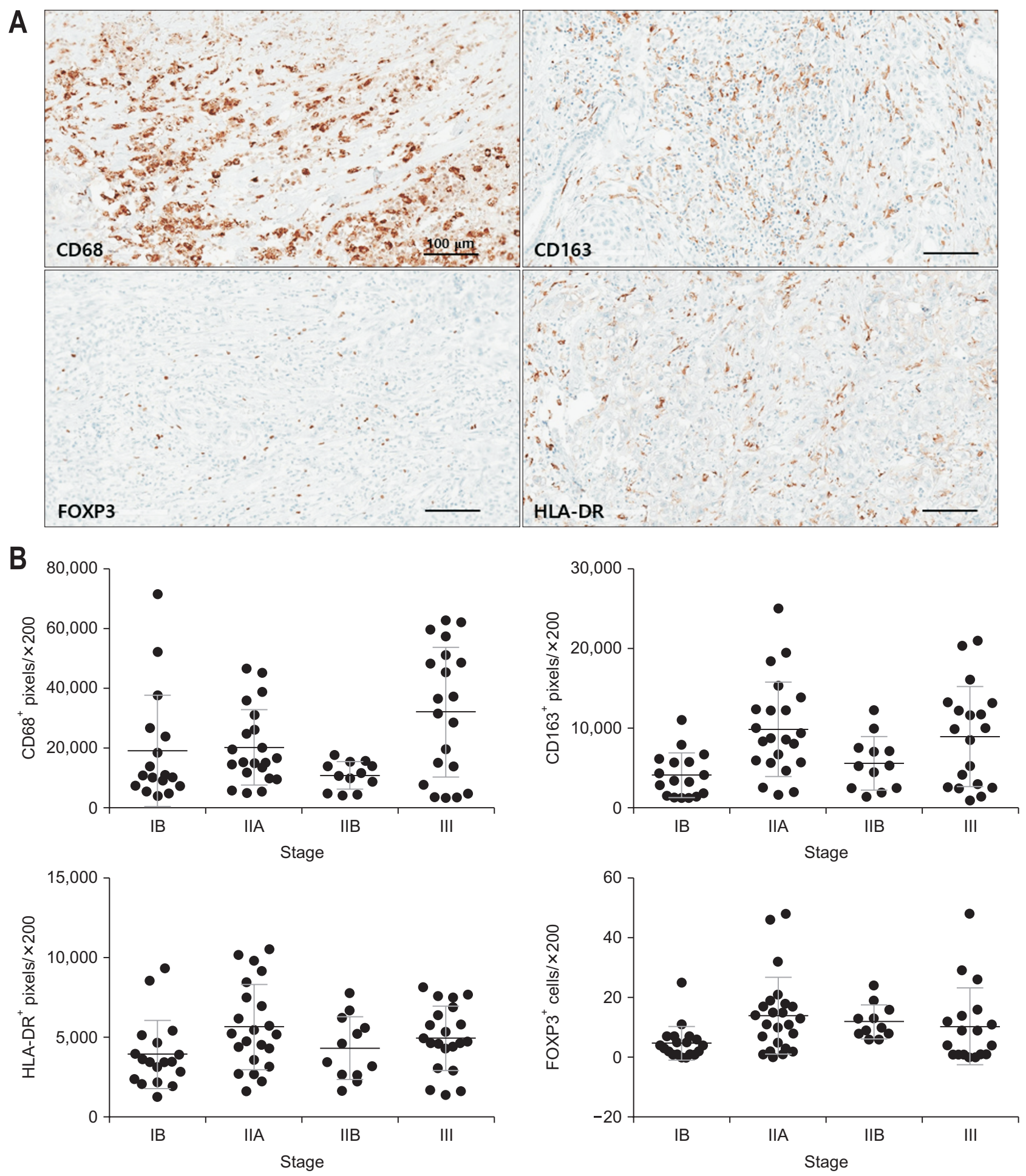

Fig. 1. Expression of macrophage and regulatory $T$ cell markers in surgically resected human pancreatic cancers $(n=12)$. (A) Representative immunohistochemical (IHC) staining ( $\times 200)$. (B) IHC expression levels according to cancer stages (Kruskal-Wallis test: $p=0.051$ for $C D 68, p=0.003$ for CD163, $p=0.118$ for HLA-DR, and $p=0.006$ for FOXP3). (C) IHC expression levels according to cancer stage (stage IB vs stage II/III). * $p<0.01$. 

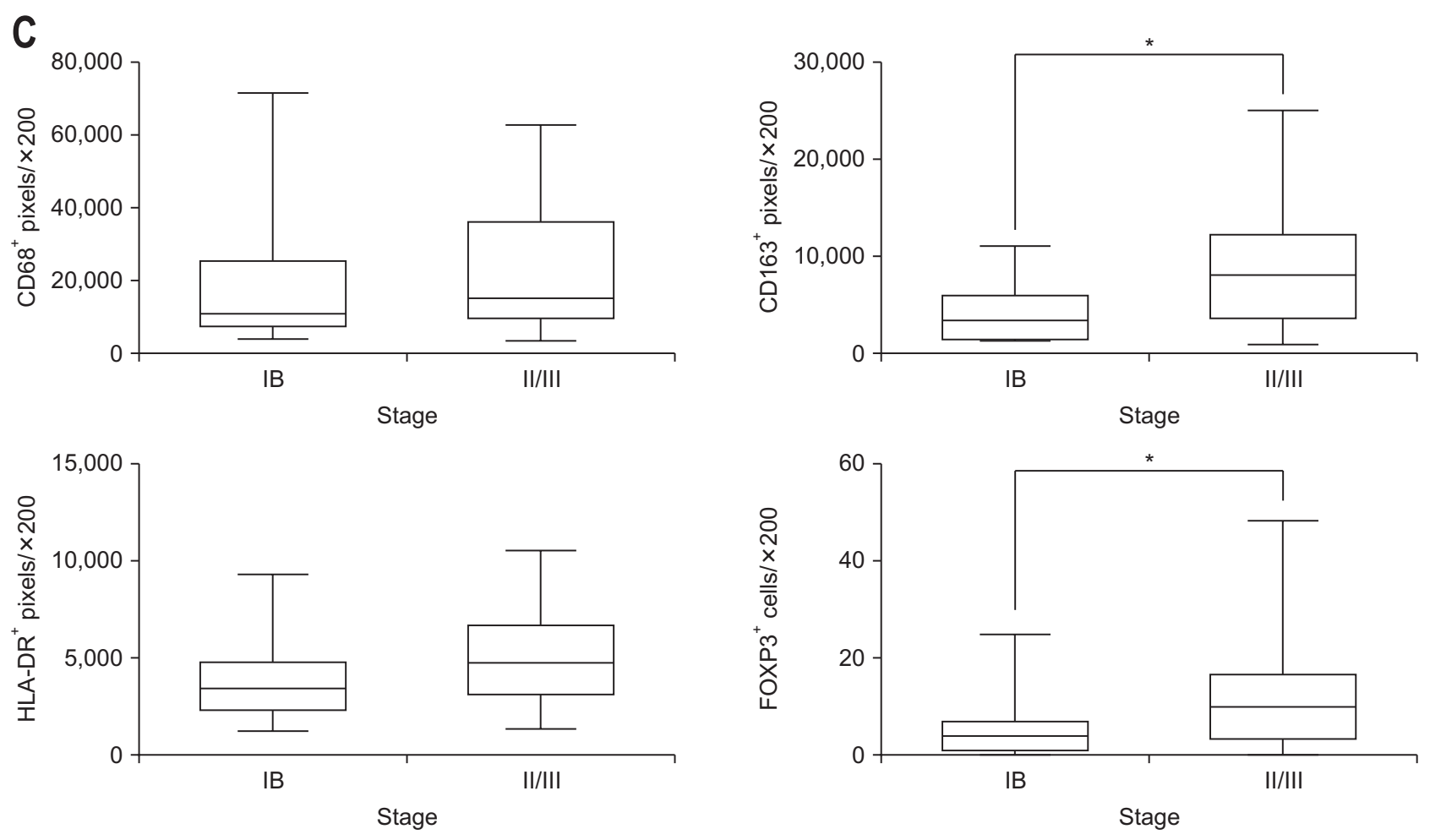

Fig. 1. Continued.

To evaluate the association between pancreatic cancer progression and macrophage phenotypes or regulatory $\mathrm{T}$ cells, the expression levels of CD68, CD163, HLA-DR, and FOXP3 were grouped according to cancer stage (Fig. 1B). Among the cancer stage groups, $\mathrm{CD}_{163}{ }^{+}$and $\mathrm{FOXP}^{+}{ }^{+}$expression levels significantly differed $(\mathrm{p}=0.003$ and $\mathrm{p}=0.006$, respectively). The patients were divided into groups based on stage (IB and II/III), and the analysis results indicated that $\mathrm{CD}_{163}{ }^{+}$and $\mathrm{FOXP}^{+}$expression levels were significantly higher in patients with stage II/III pancreatic cancer than in those with stage IB disease $(\mathrm{p}=0.002$ and $\mathrm{p}=0.003$, respectively) (Fig. 1C). These findings suggest that M2 macrophages and suppressive regulatory $\mathrm{T}$ cells are significantly related to advanced pancreatic cancer.

\section{Patients with high $\mathrm{CD}_{163^{+}}$expression had shorter overall survival}

We performed survival analysis with the four markers (CD68, CD163, HLA-DR, and FOXP3) to assess their influence on the prognosis of pancreatic cancer patients. The patients were divided into the high-expression group (more than the mean positive pixels/HPF) and lowexpression group (less than the mean positive pixels/HPF). The mean positive pixels/HPF were 21,865 for CD68, 7,553 for CD163, and 4,823 for HLA-DR. The mean number of FOXP $3^{+}$cells was 10.4 cells/HPF. Regarding CD163, patients with high $\mathrm{CD}_{163}{ }^{+}$expression levels (more than an average of 7,553 pixels/HPF) had significantly shorter overall survival than those with low $\mathrm{CD}_{163}{ }^{+}$expression levels ( $\mathrm{p}=0.002$ ) (Fig. 2). However, CD68 ${ }^{+}$, HLA-DR ${ }^{+}$, and FOXP3 $^{+}$expression levels did not show significant relationships with survival in patients with pancreatic cancer. Thus, CD163 is considered to be more closely related to overall survival than HLA-DR, CD68, and FOXP3.

\section{CD40 agonists facilitated the suppression of PANC-1 cells by shifting phenotypes of THP-1 cells}

Macrophages pretreated with PMA and lipopolysaccharide showed strong expression of CD68 and CD163 and low expression of HLA-DR, which indicated that they are predominantly M2 macrophages. In cocultures of pretreated THP-1 macrophages and PANC-1 cells, immunofluorescence staining demonstrated that CD40 agonists (2 $\mu \mathrm{g} / \mathrm{mL}$ ) led to decreased $\mathrm{CD}_{163}{ }^{+}$expression (Fig. $3 \mathrm{~A}$ ) and increased HLA-DR ${ }^{+}$expression (Fig. 3B) in THP- 1 macrophages cultured at ratios 1:1 and 1:10 (PANC-1:THP-1). Additionally, Western blot (Fig. 3C and D) showed that CD40 agonists deceased CD163 ( $\mathrm{p}=0.034)$ and increased HLA-DR ( $\mathrm{p}=0.046)$ expression at culture ratios of $1: 1$ and $1: 10$, respectively $(n=4)$. These results suggested that CD40 agonists can promote macrophage polarization toward the M1 phenotype. THP-1 macrophages significantly reduced PANC-1 proliferation after coculture $(\mathrm{p}<0.001)$, and PANC-1 proliferation decreased according to the number 

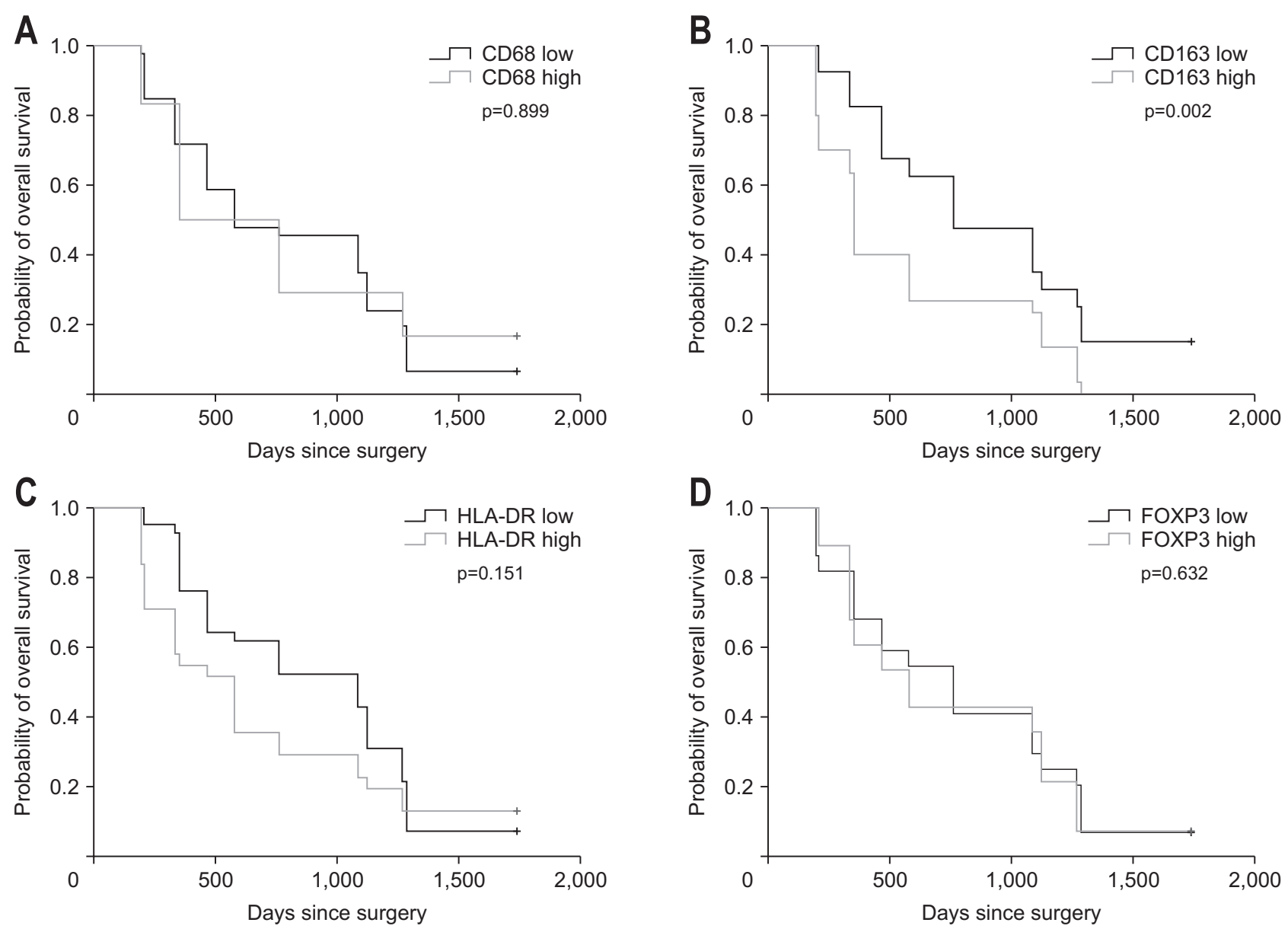

Fig. 2. Overall survival of patients with pancreatic cancer according to the expression of markers: CD68 (A), CD163 (B), HLA-DR (C), and F0XP3 (D).

of THP-1 cells and presence of CD40 agonist $(n=4)$ (Fig. 4). PANC-1 proliferation was reduced more in the 1:10 ratio coculture (10 times that of THP-1 cells) than in the $1: 1$ coculture $(p=0.026)$. Regarding CD40 agonists, the proliferation of PANC-1 cells was reduced significantly by CD40 agonists at $1: 1$ and $1: 10$ coculture ratios $(p=0.003$ and $p=0.001$, respectively). These results of the coculture experiments with CD40 agonists revealed that the suppressive effect of THP-1 macrophages on the proliferation of PANC-1 is proportional to the number of THP-1 cells, and CD40 agonists facilitate macrophages to suppress the proliferation of PANC-1 by promoting M1 polarization of THP-1 cells.

\section{Organotypic slice cultures showed that CD40 agonists shifted macrophage polarization, decreased regulatory $\mathrm{T}$ cells, and increased tumor apoptosis}

Tumor slices from eight patients with pancreatic cancer were cultured on membrane inserts in the presence or absence of CD40 agonists. The tumor slices were subjected to IHC staining (similar to surgical paraffin blocks) for
CD68, CD163, HLA-DR, FOXP3, and caspase-3 (Fig. 5A). Macrophage markers (CD68, CD163, and HLA-DR) were diffusely stained, and there was a small number of $\mathrm{FOXP}^{+}$regulatory $\mathrm{T}$ cells. CD40 agonists affected the expression of macrophage and regulatory $\mathrm{T}$ cell markers. IHC of tumor slices treated with CD40 agonists showed macrophage differentiation into the M1 phenotype with increased HLA-DR ${ }^{+}$expression and decreased $\mathrm{CD}_{163}{ }^{+}$expressions (Fig. 5B). Although a low dose of CD40 agonist $(2 \mu \mathrm{g} / \mathrm{mL})$ did not induce significant changes, a high dose $(10 \mu \mathrm{g} / \mathrm{mL})$ led to significant changes in HLA-DR ${ }^{+}$and $\mathrm{CD}_{163}{ }^{+}$expression. $\mathrm{CD}_{163^{+}}$expression levels were significantly lower in the $10 \mu \mathrm{g} / \mathrm{mL}$ CD40 agonist group than in the isotype control $(\mathrm{p}=0.014)$ and $2 \mu \mathrm{g} / \mathrm{mL}$ CD40 agonist groups $(\mathrm{p}=0.012)$, and HLA-DR ${ }^{+}$expression levels were significantly higher in the $10 \mu \mathrm{g} / \mathrm{mL}$ CD40 agonist group than in the isotype control $(\mathrm{p}<0.001)$ and $2 \mu \mathrm{g} / \mathrm{mL}$ CD40 agonist groups $(\mathrm{p}<0.001)$. CD40 agonists reduced suppressive regulatory $\mathrm{T}$ cells, with significantly lower numbers in $10 \mu \mathrm{g} / \mathrm{mL}$ CD40 agonist group than in the $2 \mu \mathrm{g} / \mathrm{mL}$ CD 40 agonist group ( $\mathrm{p}=0.009)$. The M1/M2 (HLA-DR/CD163) ratio was also significantly increased in the $10 \mu \mathrm{g} / \mathrm{mL}$ 


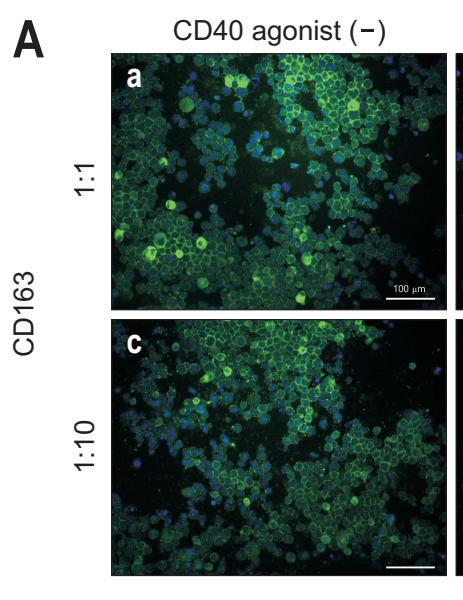

C
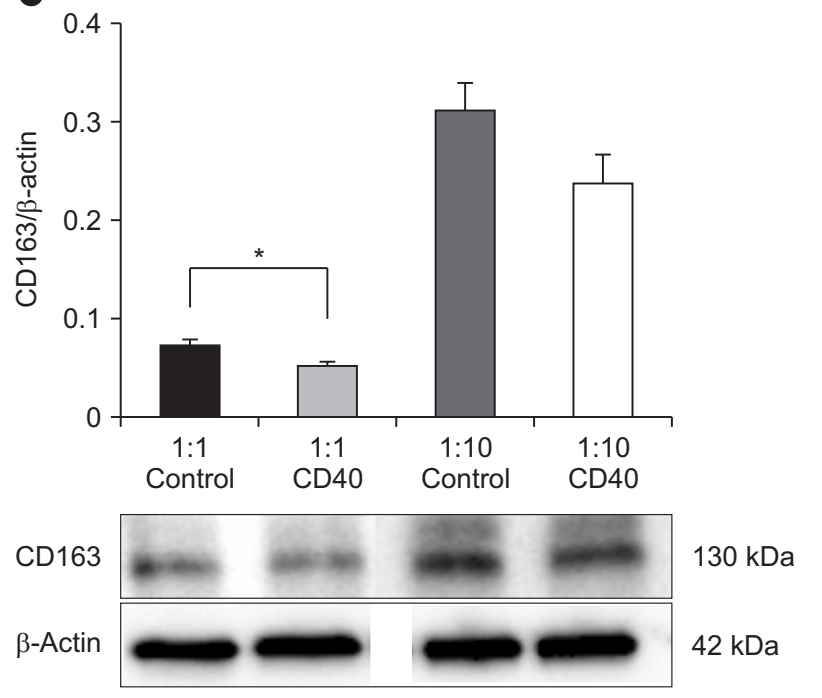

CD40 agonist $(+)$
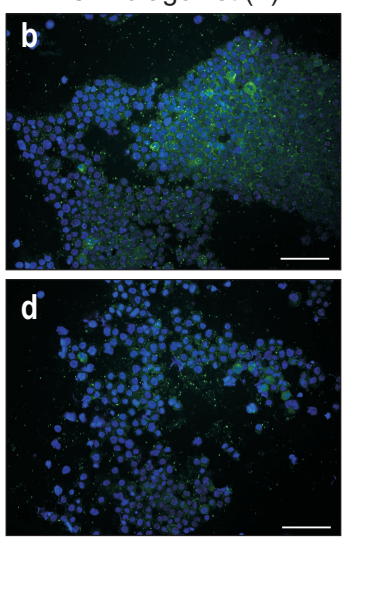
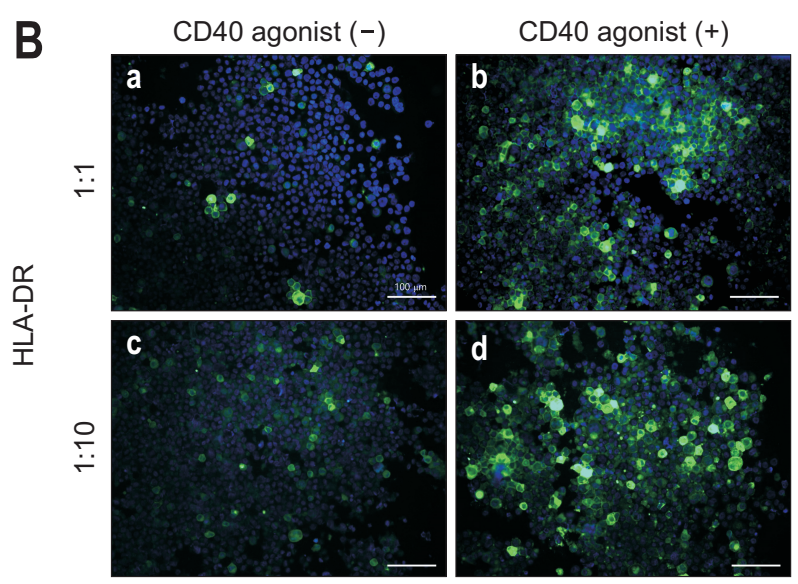

D
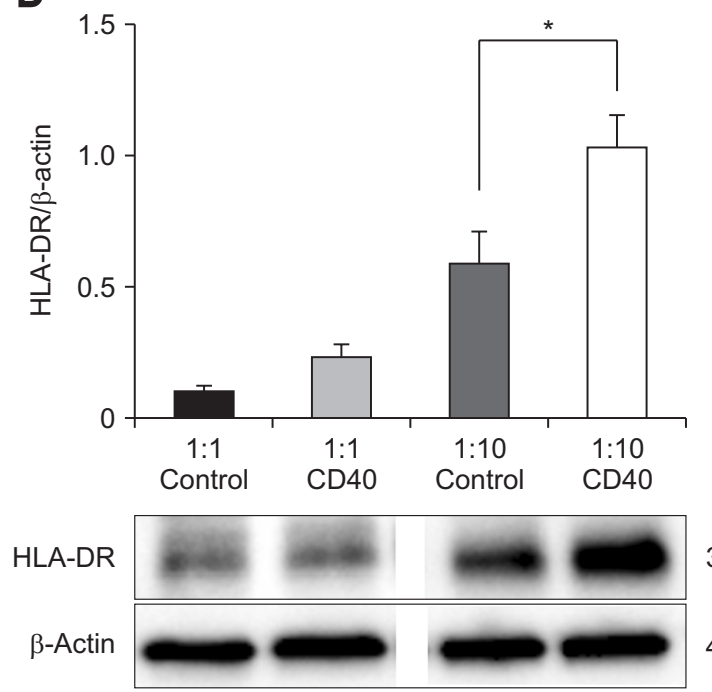

$35 \mathrm{kDa}$ $42 \mathrm{kDa}$

Fig. 3. Different expression of macrophage markers induced by CD40 agonists after coculture with PANC-1 cells and THP-1 macrophages ( $\times 200)$. Immunofluorescence staining of (A) CD163 and (B) HLA-DR expression in THP-1 cells; (a) 1:1 (PANC-1:THP-1) isotype control, (b) 1:1 CD40 agonist, (c) 1:10 isotype control, and (d) 1:10 CD40 agonist. Western blotting of (C) CD163 and (D) HLA-DR expression in THP-1 cells. *p<0.05.
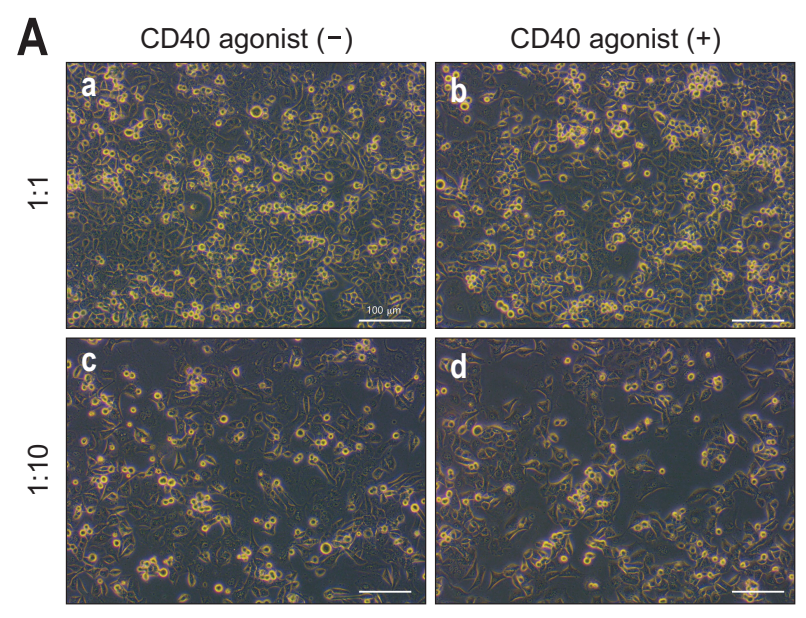

Fig. 4. Coculture of PANC-1 cells and THP-1 macrophages (×200). (A) PANC-1 cells after 4 days coculture; (a) 1:1 (PANC-1:THP-1) isotype control, (b) 1:1 CD40 agonist, (c) 1:10 isotype control, and (d) 1:10 CD40 agonist. (B) Viability (CCK8) of PANC-1 cells. ${ }^{*} p<0.05$ and ${ }^{\dagger} p<0.01$.

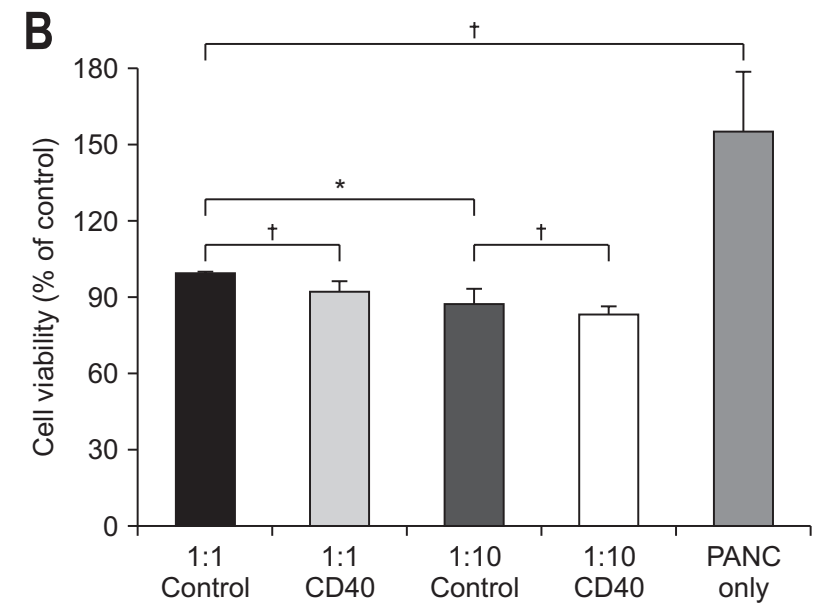



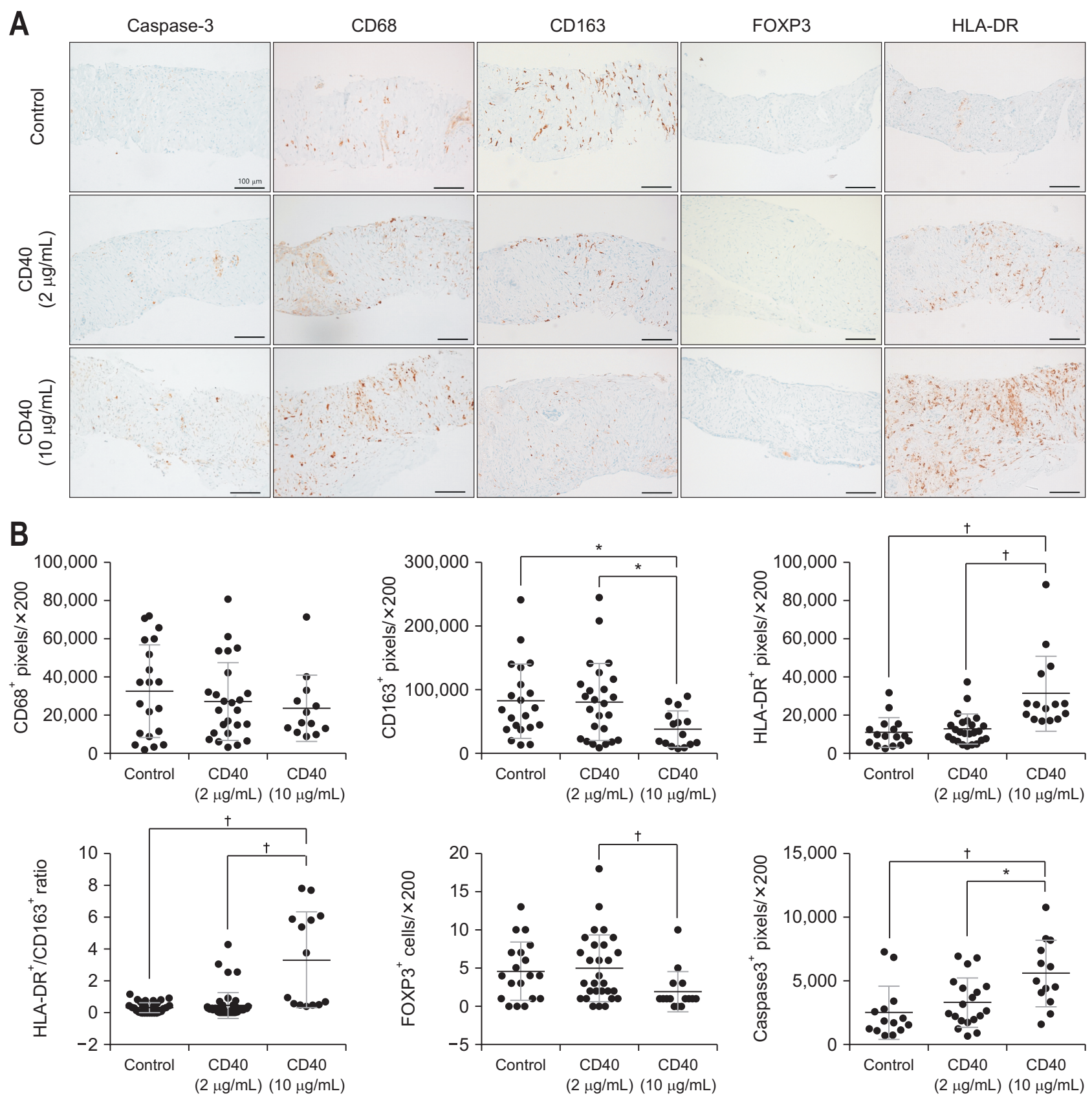

Fig. 5. Responses of human pancreatic cancer in organotypic slice culture to CD40 agonists. (A) Immunohistochemical staining of macrophage, regulatory T cells, and apoptosis markers. Rows are conditions, and columns are markers ( $\times 200$ ). (B) Expression levels of five markers after CD40 agonist treatment. (C) Comparison of differences in immunohistochemical expression between adenosquamous carcinoma and adenocarcinoma. Western blot of (D) CD163 and (E) HLA-DR expression in tumor slices ( $n=4)$. ${ }^{*} p<0.05$ and ${ }^{\dagger} p<0.01$.

CD40 agonist group compared to the control and $2 \mu \mathrm{g} / \mathrm{mL}$ CD40 agonist groups $(\mathrm{p}<0.001)$. In addition, CD40 agonists increased tumor apoptosis: caspase- $3^{+}$expression was significantly higher in the $10 \mu \mathrm{g} / \mathrm{mL}$ CD40 agonist group than in the isotype control ( $\mathrm{p}=0.002)$ and $2 \mu \mathrm{g} / \mathrm{mL} \mathrm{CD} 40$ agonist groups ( $\mathrm{p}=0.016)$. The expression levels of $\mathrm{CD} 68^{+}$, $\mathrm{CD} 163^{+}$, and $\mathrm{FOXP}^{+}$were significantly higher in adenosquamous carcinoma specimens than those in adenocarcinoma specimens ( $\mathrm{p}<0.001)$ (Fig. 5C). In addition, HLA-
$\mathrm{DR}^{+}$expression tended to be lower in adenosquamous carcinoma specimens than in adenocarcinoma specimens. This indicated that adenosquamous carcinoma has M2 characteristics and elicits greater immune suppression, which might be related to the aggressive biologic behavior of adenosquamous carcinoma. Western blot also showed a decrease in CD163 expression and an increase in HLA-DR expression in the tumor slices treated with $\mathrm{CD} 40$ agonists $(10 \mu \mathrm{g} / \mathrm{mL}), \mathrm{p}=0.032$ and $\mathrm{p}=0.041$, respectively $(\mathrm{n}=4)$ (Fig. 

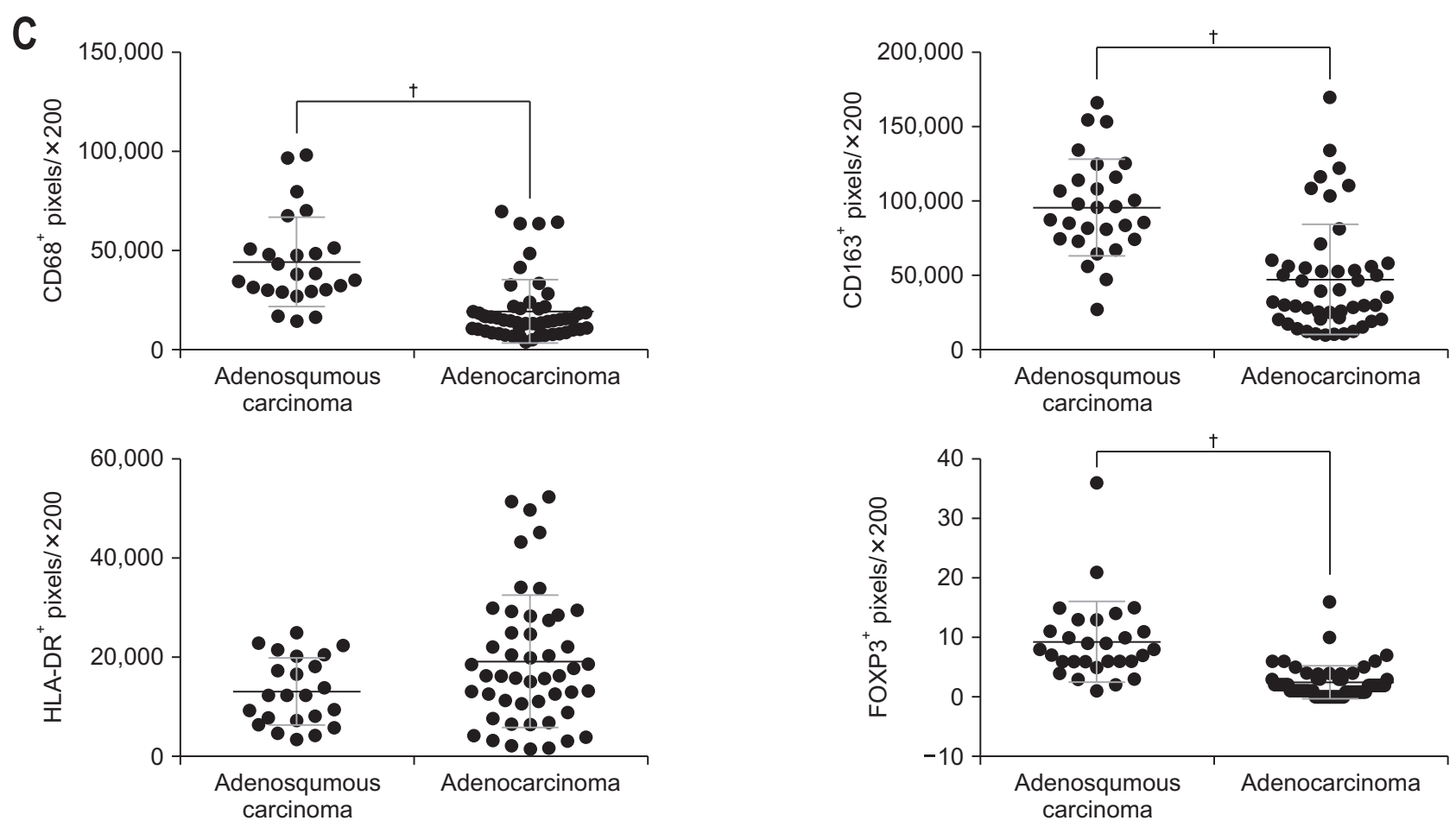

D

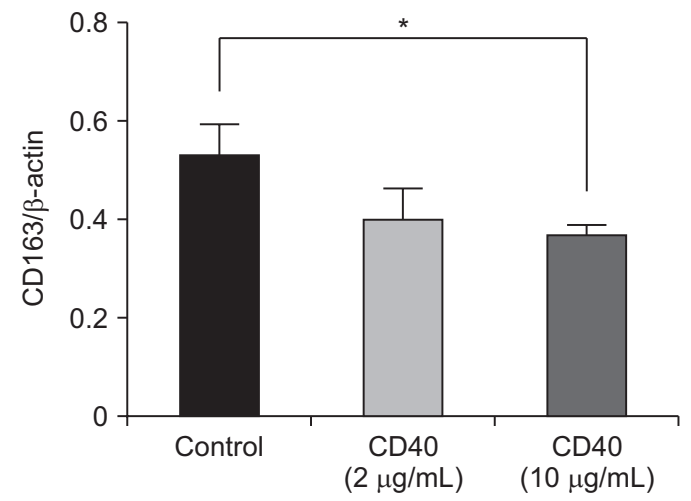

E
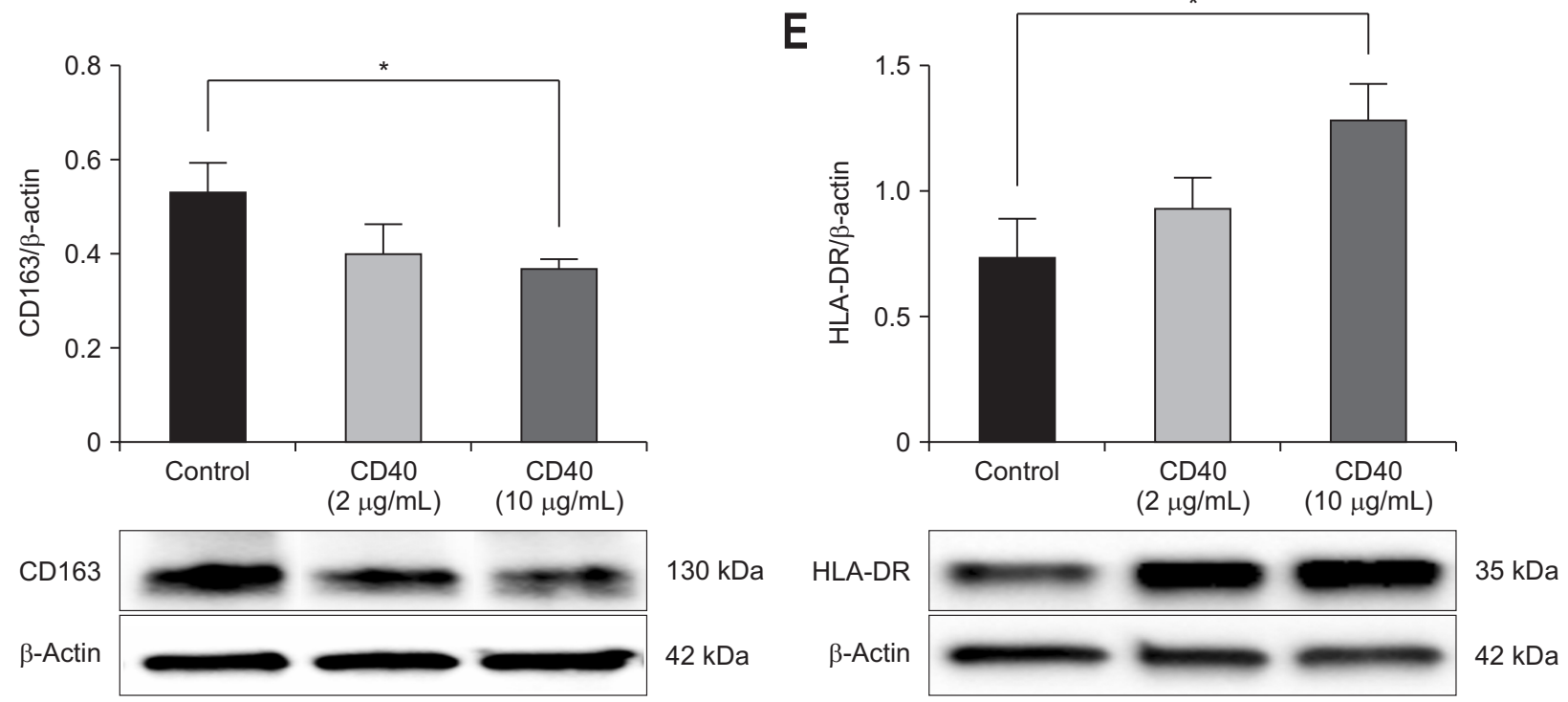

Fig. 5. Continued.

5D and $\mathrm{E})$.

\section{CD40 agonists increased TNF- $\alpha$ levels in the supernatant}

The supernatants from cell cocultures $(n=5)$ and organotypic slice cultures $(n=4)$ were collected and analyzed by ELISA to evaluate the levels of macrophage cytokine, such as TNF- $\alpha$, TGF- $\beta 1$, and IL-10 (Fig. 6). TNF- $\alpha$ is considered an M1 cytokine, and TGF- $\beta 1$ and IL-10 are considered M2 cytokines. ${ }^{2}$ In 1:10 (PANC-1:THP-1) cell

cocultures, TNF- $\alpha$ levels were significantly increased by CD40 agonists $(86.8 \pm 51.8 \mathrm{pg} / \mathrm{mL})$ compared to isotype antibody controls $(67.1 \pm 39.4 \mathrm{pg} / \mathrm{mL})(\mathrm{p}=0.036)$. In addition, TGF- $\beta 1$ and IL-10 levels showed a tendency to decrease in response to the CD40 agonist in 1:1 and 1:10 (PANC-1: THP-1) cell cocultures. These results suggest that CD40 agonists induce the production of M1 cytokines (TNF- $\alpha$ ) rather than M 2 cytokines (TGF- $\beta 1$ and IL$10)$ in cell cocultures. In organotypic slice cultures, TNF- $\alpha$ levels also increased after treatment with $2 \mu \mathrm{g} / \mathrm{mL}$ CD 40 

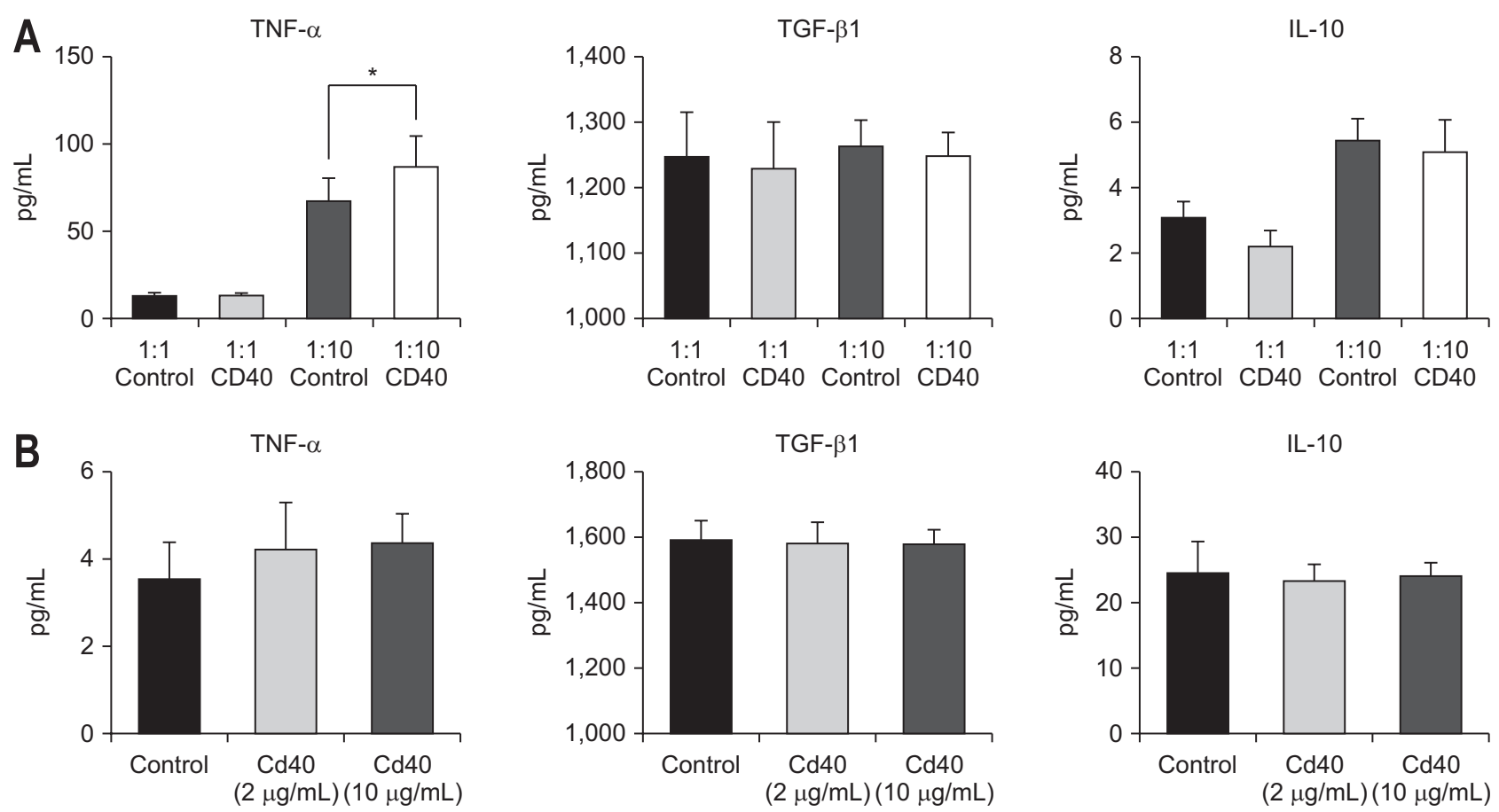

Fig. 6. Cytokine levels in the supernatants of cultures. (A) Cell cocultures and (B) organotypic slice cultures. Conditioned medium containing $10 \%$ fetal bovine serum has a TGF- $\beta 1$ concentration of $1,153 \mathrm{pg} / \mathrm{mL}$.

TNF, tumor necrosis factor; TGF, tumor growth factor; IL, interleukin. ${ }^{*} \mathrm{p}<0.05$

agonists $(4.2 \pm 3.9 \mathrm{pg} / \mathrm{mL})$ and $10 \mu \mathrm{g} / \mathrm{mL} \mathrm{CD} 40$ agonists $(4.3 \pm 2.7 \mathrm{pg} / \mathrm{mL})$ compared to isotype antibody controls $(3.5 \pm 3.5 \mathrm{pg} / \mathrm{mL})$; however, the increase was not statistically significant. TGF- $\beta 1$ and IL-10 levels in the organotypic slice cultures showed no significant changes in response to CD40 agonists. Overall TGF- $\beta 1$ and IL-10 levels in organotypic slice cultures were more than four times higher than those in cell cocultures, which indicated that the human pancreatic cancer microenvironment is more immunosuppressive, with higher levels of M2 cytokines.

\section{DISCUSSION}

The tumor microenvironment of pancreatic cancer contains a staggering milieu of cells such as immature monocytes, regulatory $\mathrm{T}$ cells, mast cells, dendritic cells, natural killer cells, neutrophils, pancreatic stellate cells, cancer-associated fibroblasts, and TAMs. ${ }^{16}$ This heterogeneous population and their interactions with tumors and stroma contribute to tumorigenesis. During tumorigenesis, dysregulated signals lead to biased expression of various immune mediators, resulting in tumor growth, tumor progression and immunosuppression including differentiation of TAMs. TAMs represent the major inflammatory component of the tumor stroma, and the stroma of pancreatic cancer has a large number of macrophages. ${ }^{17}$ TAMs have functional plasticity by adapting their phenotype to respond to stimuli and signals specific to the tumor microenvironment. According to their functions, macrophages can be broadly categorized into two subgroups; classically activated M1 or alternatively activated M2. M1 macrophages are involved in Th1 responses, which include the detection and clearance of tumor cells and the presentation of antigens to $\mathrm{T}$ cells by secreting IL- $1 \beta$, IL- 6 , and TNF- $\alpha .^{2}$ In contrast, M2 macrophages inhibit antitumor activity and induce Th2 responses by IL-10, IL-13, and TGF- $\beta .^{18}$ TAMs are traditionally characterized by $\mathrm{M} 2$ polarization, which is involved in the whole process of cancer progression from initiation to distant metastasis, including tumorigenesis, immune evasion, invasion, angiogenesis, and metastasis. ${ }^{16,19}$ Although TAMs exhibit M2 characteristics, previous studies reported that TAMs can exhibits a mix of the M2 and M1 phenotypes, ${ }^{1}$ where more than $20 \%$ of TAMs in pancreatic cancer had dual positive expression of CD163 (an M2 marker) and HLA-DR (an M1 marker), and TAMs secrete IL-1 $\beta$ as well as typical M2 cytokines. ${ }^{1}$ The present study also revealed that diffuse expression of M1 and M2 markers in human pancreatic cancer specimens.

The role of TAMs in pancreatic cancer has been actively studied. M2-polarized TAMs promoted epithelialmesenchymal transition in pancreatic cancer cells partially through the TLR4/IL-10 signaling pathway. ${ }^{6}$ TAMs induced by conditioned media from pancreatic cancer cells 
promote tumor metastasis by secreting IL- $8 .{ }^{20}$ In particular, CD163 expression was suggested as a prognostic factor in human pancreatic cancer. In 212 patients with pancreatic cancer, M2 macrophages $\left(\mathrm{CD}_{163}{ }^{+}\right.$or $\left.\mathrm{CD} 204^{+}\right)$were significantly associated with shorter survival, and $\% \mathrm{Ml}^{\text {high }}$ / $\mathrm{M} 2^{\text {low }}$ was an independent prognostic factor. ${ }^{5}$ Kurahara et al. ${ }^{21}$ showed in 76 patients with pancreatic cancer that $\mathrm{CD} 163^{+}$macrophages were related to lymph node metastasis and poor prognosis, although $\mathrm{CD} 68^{+}$macrophages had no relation to either characteristic. Another study reported in 99 patients with pancreatic cancer that dense $\mathrm{CD} 163^{+}$ M2 macrophage infiltration into the stroma was an independent prognostic factor. ${ }^{22}$ In addition, CD163 has been found to be a significant factor associated with prognosis in other malignancies, such as intrahepatic cholangiocarcinoma, ${ }^{3}$ hepatocellular carcinoma, ${ }^{4}$ and extrahepatic bile duct cancer. ${ }^{23}$ Our present study demonstrated that CD163 is significantly related to overall survival in patients with pancreatic cancer, although CD68, HLA-DR, and FOXP3 are not. The fact that CD163 is a significant factor for survival suggests that M2 macrophages are closely related to the prognosis of pancreatic cancer.

Since TAMs are associated with tumorigenesis and tumor progression, immunotherapy targeting macrophages is a promising modality to overcome insensitivity to chemoradiotherapy and improve the prognosis of pancreatic cancer patients. Several molecules that target macrophages have been studied. The chemokine ligand 2/ chemokine receptor 2 (CCR2) axis involves inhibition of macrophage recruitment from the bone marrow and migration to tumor microenvironment. In a murine pancreatic cancer model, blockade of CCR2 depletes monocytes and macrophages from the tumor, which results in enhanced antitumor immunity, decreased tumor growth, and reduced metastasis. ${ }^{24}$ Colony-stimulating factor 1 receptor blockade in pancreatic cancer models reprograms TAMs to support antitumor interferon responses and $\mathrm{T}$ cell activities, ${ }^{25}$ or to induce reduction in M2 TAM levels and increase in M1 TAM levels. ${ }^{26}$ Pancreatic cancer cells secrete Bcl-2-associated athanogene 3 (BAG3), which binds to and activates macrophages. Anti-BAG3 antibody results in reduced tumor growth and prevents metastasis formation in a pancreatic cancer mouse model. ${ }^{27}$ In addition to these targets, CD40, a member of the TNF receptor family, is a potential target that can alter macrophage activation. CD40 is a cell surface molecule on immune cells including macrophages. CD40 agonistic antibodies that bind to CD40 promote the maturation of antigen-presenting cells and enhance the tumoricidal activity of macrophages. A previous study showed that $\mathrm{CD} 40$ agonists alter the pancreatic tumor microenvironment to increase sensitivity to immune checkpoint blockade. ${ }^{28}$ In a genetically engineered mouse model of pancreatic cancer, CD40-activated macrophages rapidly infiltrated tumors and became tumoricidal independent of T cells. ${ }^{10}$ Our study demonstrated that CD40 agonists triggered macrophage polarization toward the M1 phenotype and increased TNF- $\alpha$ levels (an M1 cytokine) in cell cocultures. Additionally, CD40 agonistactivated M1 macrophages suppressed the proliferation of human pancreatic cancer cells. Our organotypic slice culture also showed the effect of CD40 agonists on macrophages in human pancreatic cancer tissues with increasing $\mathrm{HLA}_{-\mathrm{DR}}^{+}$(M1 phenotype) and decreasing $\mathrm{CD}_{163}{ }^{+}$(M2 phenotype) expression. Moreover, CD40 agonists led to a decrease in the infiltration of $\mathrm{FOXP}^{+}$suppressive regulatory $\mathrm{T}$ cells and an increase in caspase- $3^{+}$levels (indicative of apoptosis). These findings imply that CD40 agonists can trigger M1 macrophages polarization, reduce the number of infiltrating regulatory $\mathrm{T}$ cells, and induce apoptosis in human pancreatic cancer. Based on our results that CD163 expression is negatively associated with overall survival in patients with pancreatic cancer, CD40 agonists may positively affect the survival of patients.

CD40 agonists can mediate $\mathrm{T}$ cell-dependent and T cell-independent immune mechanisms of tumor regression. ${ }^{8} \mathrm{~T}$ cell-independent mechanisms modulate the immune status of the tumor microenvironment by activating macrophages and destroying the tumor stroma. ${ }^{10} \mathrm{~T}$ celldependent mechanisms involve upregulating antigen presentation and activating T cells. Previous preclinical models revealed synergistic enhancement from combining CD40 agonists with cytotoxic agents or T cell-inducing vaccines. ${ }^{11,29}$ Chemotherapy may function as a vaccine by presumably releasing tumor antigens in an immunogenic fashion. ${ }^{8}$ In our experiment, gemcitabine was combined with CD40 agonists in organotypic slice cultures to induce $\mathrm{T}$ cell-dependent effects in addition to macrophage effects. Although detailed $\mathrm{T}$ cell changes or effects were not evaluated in the present study, a decrease in regulatory $\mathrm{T}$ cells by CD40 agonists was demonstrated. Therefore, the apoptosis of pancreatic cancer observed in our study is considered to have been caused by $\mathrm{T}$ cell dependent and independent mechanisms by $\mathrm{CD} 40$ agonists.

We utilized an organotypic slice culture model in the present study. Organotypic slice cultures have been recently developed and utilized for studying several tumors including head, neck, breast, gastric, lung, and pancreatic cancers. ${ }^{30-33}$ Existing preclinical models of pancreatic cancer, such as primary cell lines, tumor xenografts, genetically engineered mouse models, and organoids, have some limitations: lack of stroma, immunocompromised environment, nonhuman species, time requirement, and 
costs. In contrast, organotypic slice culture preserves tumor cells and their unique tumor microenvironment and is an open system permitting direct and rapid access to drug treatment. ${ }^{15}$ It has been demonstrated that organotypic slice cultures of pancreatic cancer maintains viability, proliferative activity, and microenvironment during cultivation. ${ }^{15,33,34}$ Previous studies reported that this technique enables the rapid assessment of drug responses to viable pancreatic cancer tissue ex vivo and subsequent downstream analyses. ${ }^{15,35}$ Thus, organotypic slice culture would prospectively allow for the prediction of drug efficacy and identification of effective drugs in an individual cancer patient for personalized treatment.

Regarding IHC and interpretation of macrophages, there are a few controversial points. First is the lack of robust markers to quantify TAMs. We used CD68 as a pan-macrophage marker, HLA-DR as an M1 marker, and CD163 as an M2 marker, all of which are commonly used markers. However, some studies used other markers, such as CD11c and iNOS for M1 and CD204 and CD206 for M2. ${ }^{36}$ Although CD68 is a pan-macrophage marker, it is not specific for the monocyte/macrophage system and can be immunohistochemically detectable in a variety of other cell types. In addition, CD163 is an M2 macrophage marker but is also expressed in some dendritic and endothelial cells. ${ }^{37}$ This could result in inaccurate M1 and M2 TAM counts. Second, it is difficult to quantify M1 and M2 TAMs in a tissue section, which is prone to bias and interobservational discrepancies. Digital image analysis can help reduce subjective human errors, ensuring precise and accurate results each time. ${ }^{36}$ However, this application could incorrectly misidentify cells such as dendritic and endothelial cells as TAMs. In the present study, we used digital image analysis to reduce such bias. Since macrophage markers were stained diffusely and macrophages cannot be distinguished clearly, we utilized stained pixels interpreted by ImageJ. Although the pixels could include a few components other than macrophages, they did not hinder the relative comparison of responses by CD40 agonists. To support our findings, ELISA analysis of cytokine profiling in the supernatants was added. Although CD163 was related to survival in the present study, it cannot be concluded that CD163 affects survival independently due to the various factors affecting survival and the relatively small number of patients analyzed. However, we evaluated as many as 6 to 8 HPFs of surgically resected specimens per patient to obtain as much data as possible.

In summary, human pancreatic cancer showed more M2 polarization of macrophages, and CD163 was associated with advanced cancer stages and shorter overall survival in patients with pancreatic cancer. CD40 agonists alter macrophage differentiation to favor the M1 phenotype and suppress the proliferation of human pancreatic cancer cells in cell coculture. Organotypic slice culture demonstrated that CD40 agonists induce M1 polarization of TAMs and increase the apoptosis of human pancreatic cancer.

\section{CONFLICTS OF INTERSET}

No potential conflict of interest relevant to this article was reported.

\section{ACKNOWLEDGEMENTS}

This research was supported by the Institute of Clinical Medicine Research of Bucheon St. Mary's Hospital, South Korea (Research Fund, BCMC20IH01) and the Basic Science Research Program through the National Research Foundation of Korea (NRF) funded by the Ministry of Education (number: 2016R1D1A1B03931040).

\section{AUTHOR CONTRIBUTIONS}

Study concept and design: J.H.C., C.Y.L. Methodology: C.Y.L., J.H.C., W.S.L. Materials: I.Y.P. Experiments: C.Y.L., J.H.C., W.S.L. Funding acquisition: J.H.C. Pathologic review: J.H.C., J.K. Writing - original draft: J.H.C. Writing review and editing: C.Y.L., W.S.L. Approval of final manuscript: all authors.

\section{ORCID}

Chae Yoon Lim https://orcid.org/0000-0001-9645-1030 Jae Hyuck Chang https://orcid.org/0000-0003-1180-2693 Won Sun Lee https://orcid.org/0000-0003-3043-0071 Jeana Kim https://orcid.org/0000-0003-1021-0290 Il Young Park https://orcid.org/0000-0003-4590-2297

\section{REFERENCES}

1. Helm O, Held-Feindt J, Grage-Griebenow E, et al. Tumorassociated macrophages exhibit pro- and anti-inflammatory properties by which they impact on pancreatic tumorigenesis. Int J Cancer 2014;135:843-861.

2. Sica A, Larghi P, Mancino A, et al. Macrophage polarization in tumour progression. Semin Cancer Biol 2008;18:349-355.

3. Hasita H, Komohara Y, Okabe H, et al. Significance of alternatively activated macrophages in patients with intrahepatic 
cholangiocarcinoma. Cancer Sci 2010;101:1913-1919.

4. Minami K, Hiwatashi K, Ueno S, et al. Prognostic significance of CD68, CD163 and Folate receptor- $\beta$ positive macrophages in hepatocellular carcinoma. Exp Ther Med 2018; 15:4465-4476

5. Ino Y, Yamazaki-Itoh R, Shimada K, et al. Immune cell infiltration as an indicator of the immune microenvironment of pancreatic cancer. Br J Cancer 2013;108:914-923.

6. Liu CY, Xu JY, Shi XY, et al. M2-polarized tumor-associated macrophages promoted epithelial-mesenchymal transition in pancreatic cancer cells, partially through TLR4/IL-10 signaling pathway. Lab Invest 2013;93:844-854.

7. Zhu Y, Herndon JM, Sojka DK, et al. Tissue-resident macrophages in pancreatic ductal adenocarcinoma originate from embryonic hematopoiesis and promote tumor progression. Immunity 2017;47:323-338.

8. Vonderheide RH, Bajor DL, Winograd R, Evans RA, Bayne LJ, Beatty GL. CD40 immunotherapy for pancreatic cancer. Cancer Immunol Immunother 2013;62:949-954.

9. Schoenberger SP, Toes RE, van der Voort EI, Offringa R, Melief CJ. T-cell help for cytotoxic T lymphocytes is mediated by CD40-CD40L interactions. Nature 1998;393:480-483.

10. Beatty GL, Chiorean EG, Fishman MP, et al. CD40 agonists alter tumor stroma and show efficacy against pancreatic carcinoma in mice and humans. Science 2011;331:1612-1616.

11. Byrne KT, Vonderheide RH. CD40 stimulation obviates innate sensors and drives T cell immunity in cancer. Cell Rep 2016;15:2719-2732.

12. O’Sullivan T, Saddawi-Konefka R, Vermi W, et al. Cancer immunoediting by the innate immune system in the absence of adaptive immunity. J Exp Med 2012;209:1869-1882.

13. Rakhmilevich AL, Buhtoiarov IN, Malkovsky M, Sondel PM. CD40 ligation in vivo can induce $\mathrm{T}$ cell independent antitumor effects even against immunogenic tumors. Cancer Immunol Immunother 2008;57:1151-1160.

14. Buhtoiarov IN, Lum H, Berke G, Paulnock DM, Sondel PM, Rakhmilevich AL. CD40 ligation activates murine macrophages via an IFN-gamma-dependent mechanism resulting in tumor cell destruction in vitro. J Immunol 2005;174:60136022 .

15. Lim CY, Chang JH, Lee WS, et al. Organotypic slice cultures of pancreatic ductal adenocarcinoma preserve the tumor microenvironment and provide a platform for drug response. Pancreatology 2018;18:913-927.

16. Lankadasari MB, Mukhopadhyay P, Mohammed S, Harikumar KB. TAMing pancreatic cancer: combat with a double edged sword. Mol Cancer 2019;18:48.

17. Mielgo A, Schmid MC. Impact of tumour associated macrophages in pancreatic cancer. BMB Rep 2013;46:131-138.

18. Sica A, Schioppa T, Mantovani A, Allavena P. Tumour-associated macrophages are a distinct M2 polarised population promoting tumour progression: potential targets of anticancer therapy. Eur J Cancer 2006;42:717-727.

19. Yang J, Li Y, Sun Z, Zhan H. Macrophages in pancreatic cancer: an immunometabolic perspective. Cancer Lett 2021;498: 188-200.

20. Chen SJ, Lian GD, Li JJ, et al. Tumor-driven like macrophages induced by conditioned media from pancreatic ductal adenocarcinoma promote tumor metastasis via secreting IL-8. Cancer Med 2018;7:5679-5690.

21. Kurahara H, Shinchi H, Mataki Y, et al. Significance of M2polarized tumor-associated macrophage in pancreatic cancer. J Surg Res 2011;167:e211-e219.

22. Hu H, Hang JJ, Han T, Zhuo M, Jiao F, Wang LW. The M2 phenotype of tumor-associated macrophages in the stroma confers a poor prognosis in pancreatic cancer. Tumour Biol 2016;37:8657-8664.

23. Miura T, Yoshizawa T, Hirai H, et al. Prognostic impact of CD163+ macrophages in tumor stroma and CD8+ T-cells in cancer cell nests in invasive extrahepatic bile duct cancer. Anticancer Res 2017;37:183-190.

24. Sanford DE, Belt BA, Panni RZ, et al. Inflammatory monocyte mobilization decreases patient survival in pancreatic cancer: a role for targeting the CCL2/CCR2 axis. Clin Cancer Res 2013;19:3404-3415.

25. Zhu Y, Knolhoff BL, Meyer MA, et al. CSF1/CSF1R blockade reprograms tumor-infiltrating macrophages and improves response to T-cell checkpoint immunotherapy in pancreatic cancer models. Cancer Res 2014;74:5057-5069.

26. Li M, Li M, Yang Y, et al. Remodeling tumor immune microenvironment via targeted blockade of PI3K- $\gamma$ and CSF$1 / \mathrm{CSF}-1 \mathrm{R}$ pathways in tumor associated macrophages for pancreatic cancer therapy. J Control Release 2020;321:23-35.

27. Rosati A, Basile A, D’Auria R, et al. BAG3 promotes pancreatic ductal adenocarcinoma growth by activating stromal macrophages. Nat Commun 2015;6:8695.

28. Luheshi NM, Coates-Ulrichsen J, Harper J, et al. Transformation of the tumour microenvironment by a CD40 agonist antibody correlates with improved responses to PD-L1 blockade in a mouse orthotopic pancreatic tumour model. Oncotarget 2016;7:18508-18520.

29. Ma HS, Poudel B, Torres ER, et al. A CD40 agonist and PD-1 antagonist antibody reprogram the microenvironment of nonimmunogenic tumors to allow T-cell-mediated anticancer activity. Cancer Immunol Res 2019;7:428-442.

30. Gerlach MM, Merz F, Wichmann G, et al. Slice cultures from head and neck squamous cell carcinoma: a novel test system for drug susceptibility and mechanisms of resistance. Br J Cancer 2014;110:479-488.

31. Koerfer J, Kallendrusch S, Merz F, et al. Organotypic slice cultures of human gastric and esophagogastric junction cancer. Cancer Med 2016;5:1444-1453. 
32. Naipal KA, Verkaik NS, Sánchez H, et al. Tumor slice culture system to assess drug response of primary breast cancer. BMC Cancer 2016;16:78.

33. Jiang X, Seo YD, Chang JH, et al. Long-lived pancreatic ductal adenocarcinoma slice cultures enable precise study of the immune microenvironment. Oncoimmunology 2017;6: e1333210.

34. Misra S, Moro CF, Del Chiaro M, et al. Ex vivo organotypic culture system of precision-cut slices of human pancreatic ductal adenocarcinoma. Sci Rep 2019;9:2133.

35. Seo YD, Jiang X, Sullivan KM, et al. Mobilization of CD8+ T cells via CXCR4 blockade facilitates PD-1 checkpoint ther- apy in human pancreatic cancer. Clin Cancer Res 2019;25: 3934-3945.

36. Jayasingam SD, Citartan M, Thang TH, Mat Zin AA, Ang $\mathrm{KC}$, Ch'ng ES. Evaluating the polarization of tumor-associated macrophages into M1 and M2 phenotypes in human cancer tissue: technicalities and challenges in routine clinical practice. Front Oncol 2020;9:1512.

37. Hu JM, Liu K, Liu JH, et al. CD163 as a marker of M2 macrophage, contribute to predicte aggressiveness and prognosis of Kazakh esophageal squamous cell carcinoma. Oncotarget 2017;8:21526-21538. 